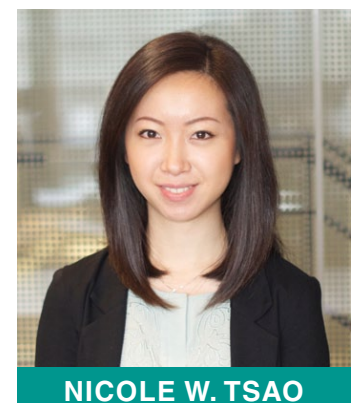

Provincial policies have been rapidly evolving to allow pharmacists to provide expanded pharmaceutical care services. However, with this comes growing concern that the pharmacy workplace environment is not evolving alongside these changes in practice. We conducted a survey of pharmacists in British Columbia to determine their opinions on their working environments.

Les politiques provinciales évoluent rapidement pour permettre aux pharmaciens d'offrir davantage de soins pharmaceutiques. Il y a toutefois une crainte croissante que le milieu de travail des pharmacies ne soit pas en phase avec cette évolution de la pratique. Nous avons mené une enquête auprès des pharmaciens de la Colombie-Britannique pour connaître leur opinion sur leur milieu de travail.

(C) The Author(s) 2015 DOl: 10.1177/1715163515617777

\title{
Factors associated with
} pharmacists' perceptions of their working conditions and safety and
effectiveness of patient care

\author{
Nicole W. Tsao, BSc(Pharm), MScPharm; Larry D. Lynd, BSP, PhD; \\ Louise Gastonguay, BSc, MSA; Kathy Li, PhD; Bob Nakagawa, BSc(Pharm); \\ Carlo A. Marra, BSc(Pharm), PharmD, PhD
}

\section{ABSTRACT}

Background: In recent years, the role of pharmacists has changed, as have various provincial legislations, which now allow pharmacists to provide additional health services to patients. With these changes comes growing concern about how well the current pharmacy working environment is adapting and whether it may also be creating work-related stress that may contribute to potentially unsafe practices of patient care.

Methods: To characterize the current working conditions of pharmacists in British Columbia, an online survey was developed and distributed to all College of Pharmacists of $B C$ (CPBC) registrants by email. The survey consisted of questions on pharmacists' demographics, practice setting and perceptions of workplace conditions. Responses were collected from October 1 to November 10, 2013. All data were summarized using descriptive statistics, and regression models were constructed to assess the association between various factors and pharmacists' self-reported working conditions.

Results: Twenty-three percent (1241/5300) of pharmacists registered with the CPBC responded, with $78 \%$ working in the community pharmacy setting (58\% chain, 19\% independent). Pharmacists mostly disagreed with the statements that they had enough time for breaks or lunches or to do their jobs, as well as enough staffing support. Pharmacists' perceptions of their workplace environment were negatively associated with workplace-imposed advanced service quotas (for medication reviews, immunizations and prescription adaptations); being employed at chain store pharmacies, compared to independent pharmacies or hospitals/long-term care settings; and higher prescription volume.

Discussion: Pharmacists working in chain community pharmacies who are required to meet monthly quotas for expanded services reported a substantial negative impact on their working conditions and perceived safety of patient care. Can Pharm J (Ott) 2016;149:18-27.

\section{Introduction}

Workplace stress that may compromise patient safety is a growing concern in community pharmacies in various countries, including Canada, ${ }^{1}$ the United Kingdom, ${ }^{2}$ the United
States $^{3}$ and Australia. ${ }^{4}$ Reasons for this increase in stress include the changing pattern of pharmacy ownership, with more corporate entities enforcing business-related demands on pharmacists, leading to reduced professional 
autonomy, ${ }^{5}$ provision of expanded scope and enhanced services without relaxation or delegation of traditional roles ${ }^{2,6}$ and insufficient or inefficient use of pharmacist extenders such as technicians. ${ }^{7}$ In addition, higher prescription volumes, lack of breaks, workflow interruptions and staffing levels were other issues identified as potentially contributing to dispensing errors. ${ }^{3,8-10}$

A survey conducted by the Oregon Pharmacy Board in 2011 elicited pharmacists' opinions on various workplace factors and safety of patient care. ${ }^{11}$ The Oregon survey found that more than $50 \%$ of pharmacists working in chain community pharmacies disagreed or strongly disagreed with the statement that they had a work environment that was conducive to providing safe and effective patient care. ${ }^{11}$ The board also received more than 500 written comments from pharmacist respondents, with numerous negative remarks on the state of pharmacy workplace conditions in Oregon. Due to these results, the Oregon Pharmacy Board adopted new rules to address the operation of pharmacies to ensure patient safety-some of those rules included requiring pharmacies to provide pharmacists with sufficient opportunities for uninterrupted rest, to allow adequate time for pharmacists to complete professional duties and prohibition of productivity quotas or time limits that interfere with pharmacists' ability to provide appropriate professional services. ${ }^{12}$ The Oregon Pharmacy Board was later commended for this with the National Association of Boards of Pharmacy Fred T. Mahaffey Award, which recognizes a member board of pharmacy that has made a substantial contribution to the protection of public health and welfare. ${ }^{13}$

In British Columbia (BC), the regulatory body (the College of Pharmacists of British Columbia $[\mathrm{CPBC}])$ perceived that a number of factors (including those listed above) could also be creating highly stressful workplace environments that might contribute to potentially unsafe practices for patient care. As such, the objective of this study was to characterize the current working conditions of pharmacists in $\mathrm{BC}$ and evaluate the association between the provision of advanced pharmacy services and pharmacist/pharmacy characteristics and workplace conditions.

\section{Methods}

Study design

This study was a cross-sectional survey sent to all pharmacists registered with the $\mathrm{CPBC}$ in $\mathrm{BC}$,

\section{KNOWLEDGE INTO PRACTICE}

- In this survey of pharmacists in British Columbia, we found that pharmacists working in pharmacies that imposed quotas for providing advanced pharmacy services had especially negative perceptions of their working conditions.

- Higher prescription volume and being employed by a chain store were also negatively associated with workplace conditions.

- Characterizing and understanding these phenomena provide an opportunity to inform pharmacy practice policies, improve pharmacists' working conditions and ensure safer patient care.

Canada. The survey was adapted from the Oregon Board of Pharmacy survey on pharmacists' working conditions in Oregon, United States, ${ }^{11}$ with additional elements included. With the assistance of the $\mathrm{CPBC}$, all pharmacist registrants were sent an email invitation describing the survey and inviting them to respond online. A link was embedded within the email invitation that could be used by respondents to complete the survey instrument. The data were collected from October 1, 2013, to November 10, 2013; potential respondents were sent 2 email reminders during this period to prompt participation and completion of the survey. This study was approved by the University of British Columbia Behavioural Research Ethics Board.

\section{Survey}

The first section contained basic demographic and practice setting questions. Specifically, respondents were asked to indicate their sex, birth year, number of years as a registered pharmacist, education, primary practice site and primary pharmacy role. Section 2 contained questions about the respondents' current practice setting and advanced practice services offered to patients. Finally, additional questions covered typical work hours, average prescription volume and wait time, and physical aspects of the pharmacy where the respondent worked. This section was also adapted from the Oregon survey to reflect the pharmacy services currently being reimbursed in BC, which included prescription adaptations (renewing a prescription; changing the dose, formulation or instructions of a prescription; or therapeutic substitution), immunizations, and medication reviews (producing a best possible medication history and identifying and resolving drug therapy problems). In particular, questions 


\section{MISE EN PRATIQUE DES CONNAISSANCES}

- Nous y avons constaté que les pharmaciens de la C.-B. travaillant dans des établissements imposant des quotas sur la prestation de services de pharmacie avancés avaient une opinion particulièrement négative de leurs conditions de travail.

- Les participants soumis à un volume élevé d'ordonnances et au travail dans une grande chaîne avaient aussi une perception négative des conditions de travail.

- La caractérisation et la compréhension de ces phénomènes permettent d'éclairer les politiques sur l'exercice de la pharmacie, d'améliorer les conditions de travail des pharmaciens et de renforcer la sécurité des soins aux patients. were asked about the number of prescription adaptations, immunizations and medication reviews provided each month. Respondents were also asked whether their practice site imposed monthly quotas for each of the advanced practice services and what the quota amount was.

Six specific questions pertained to the assessment of the workplace conditions of each responding pharmacist. Using a 5-point Likert scale (ranging from $1=$ strongly disagree to $5=$ strongly agree), respondents were asked to rate their agreement with the statements presented in Table 1.

\section{Analysis}

All variables were summarized using descriptive statistics. Prior to inferential analyses, answers to the 6 workplace conditions questions were collapsed into those who "disagreed" with the statement (rating 1 or 2 ), those who were "neutral" (rating 3) and those who "agreed" (rating 4 or 5), to allow for more equal distribution of responses across groups. Due to the open-ended format of the questions asking respondents to report monthly quota amounts for each of the services (i.e., prescription adaptations, immunizations and medication reviews), we made every attempt to estimate and standardize the responses to "frequency of service provided, per pharmacist, per month" for prescription adaptations and medication reviews. For immunizations, responses were standardized to "frequency provided, per month, per influenza season"; the influenza season was assumed to be approximately 5 months a year from October to March. Univariate analyses of demographic variables were examined, means and standard deviations were calculated for continuous variables, frequencies or proportions were computed for categorical variables and bivariate relationships between demographic variables and the 6 workplace conditions were examined. Those variables that were significant at $p<0.05$ were considered covariates in multivariate models. To explore differences in pharmacists' workplace conditions, we developed ordinal logistic regression models to examine the relationships between pharmacist and practice site characteristics and pharmacists' level of agreement with the workplace condition statements. All analyses were performed in SAS version 9.3 (SAS Institute, Cary, North Carolina).

\section{Results}

Of 5300 registered pharmacists in BC, 1241 (23\%) responded, $61 \%$ of whom were female; the mean age was 42 (SD 11.7) years (Table 2). Seventy-eight percent of respondents practised in a community pharmacy setting (58\% chain and 19\% independently owned), while $69 \%$ were staff pharmacists and $28 \%$ were pharmacy managers.

TABLE 1 Statements on pharmacists' working conditions presented in the survey

\begin{tabular}{ll}
\hline Workplace condition & Likert-scaled statements \\
\hline Time for breaks & "I have adequate time for break/lunches at my primary practice site" \\
\hline Time for job tasks & "I am satisfied with the amount of time I have to do my job" \\
\hline $\begin{array}{l}\text { Work environment for safe and effective } \\
\text { care }\end{array}$ & $\begin{array}{c}\text { "My employer provides a work environment that is conducive to safe and effective } \\
\text { primary care" }\end{array}$ \\
\hline Adequate pharmacist staffing & "My site has adequate pharmacist staff to provide safe and effective patient care" \\
\hline Adequate technician staffing & "My site has adequate technician staff to provide safe and effective patient care" \\
\hline Adequate assistant staffing & "My site has adequate assistant staff to provide safe and effective patient care" \\
\hline
\end{tabular}


TABLE 2 Respondent demographics

\begin{tabular}{lc}
\hline Characteristic & Percent $(\boldsymbol{n}=\mathbf{1 2 4 1})$ \\
\hline Sex & 39.2 \\
\hline Male & 60.8 \\
\hline Female & $42(11.7)$ \\
\hline Age, mean (SD) & $16(12.3)$ \\
\hline Years as registered pharmacist, mean (SD) & Percent $(n=1134)$ \\
\hline Credentials & 79.8 \\
\hline BScPharm & 2.2 \\
\hline MSc & 4.8 \\
\hline PharmD & 13.5 \\
\hline Other & Percent $(n=1139)$ \\
\hline Primary practice site & 18.5 \\
\hline Independent community pharmacy & 57.7 \\
\hline Chain community pharmacy & 17.1 \\
\hline Hospital/long-term care & 6.7 \\
\hline Other (academic institution, research organization, industry, specialty pharmacy) & Percent $(n=1131)$ \\
\hline Primary role & 52.6 \\
\hline Staff pharmacist & 11.1 \\
\hline Specialist pharmacist & 28.5 \\
\hline Pharmacy manager & 7.7 \\
\hline Other & \\
\hline
\end{tabular}

The majority of respondents (69\%) typically worked up to 40 hours a week, while $31 \%$ of respondents reported typically working more than 40 hours a week. Most respondents $(60 \%)$ reported that their site processed $\leq 100$ prescriptions per pharmacist per day, while $29 \%$ and $11 \%$ reported processing 101 to 200 prescriptions and more than 200 prescriptions per pharmacist per day, respectively. Sixtyeight percent of respondents reported having an average prescription wait time of $\leq 20$ minutes. The physical characteristics of respondents' pharmacies were reported as follows: $73 \%$ of pharmacies had a private consultation area, $95 \%$ had a seated waiting area, $43 \%$ felt their pharmacy was spacious, $29 \%$ felt their pharmacy was neither spacious nor crammed and $28 \%$ reported their pharmacy as not having enough space. Most pharmacies (95\%) provided 2 or more advanced reimbursable pharmacy services such as prescription adaptations, immunizations or medication reviews.
Figure 1 shows the percentage of respondents who reported that their sites imposed monthly quotas on prescription adaptations (10\%), immunizations (15\%) and medication reviews (42\%). Figure 2 shows the same results stratified by pharmacy type. We found that the frequency of providing advanced practice services was strongly and positively associated with average monthly quotas; however, this was based on a small number of respondents (Figure 3).

Overall, respondents mostly disagreed with the statements relating to having enough time for breaks/lunches and enough time for job tasks (Table 3). Conversely, respondents mostly agreed that they had a work environment conducive to providing safe and effective care and having adequate assistant staffing, and they were mostly neutral to the statement relating to having adequate technician staffing.

When the relationships between each demographic and pharmacy factor and workplace condition was explored independently, without 

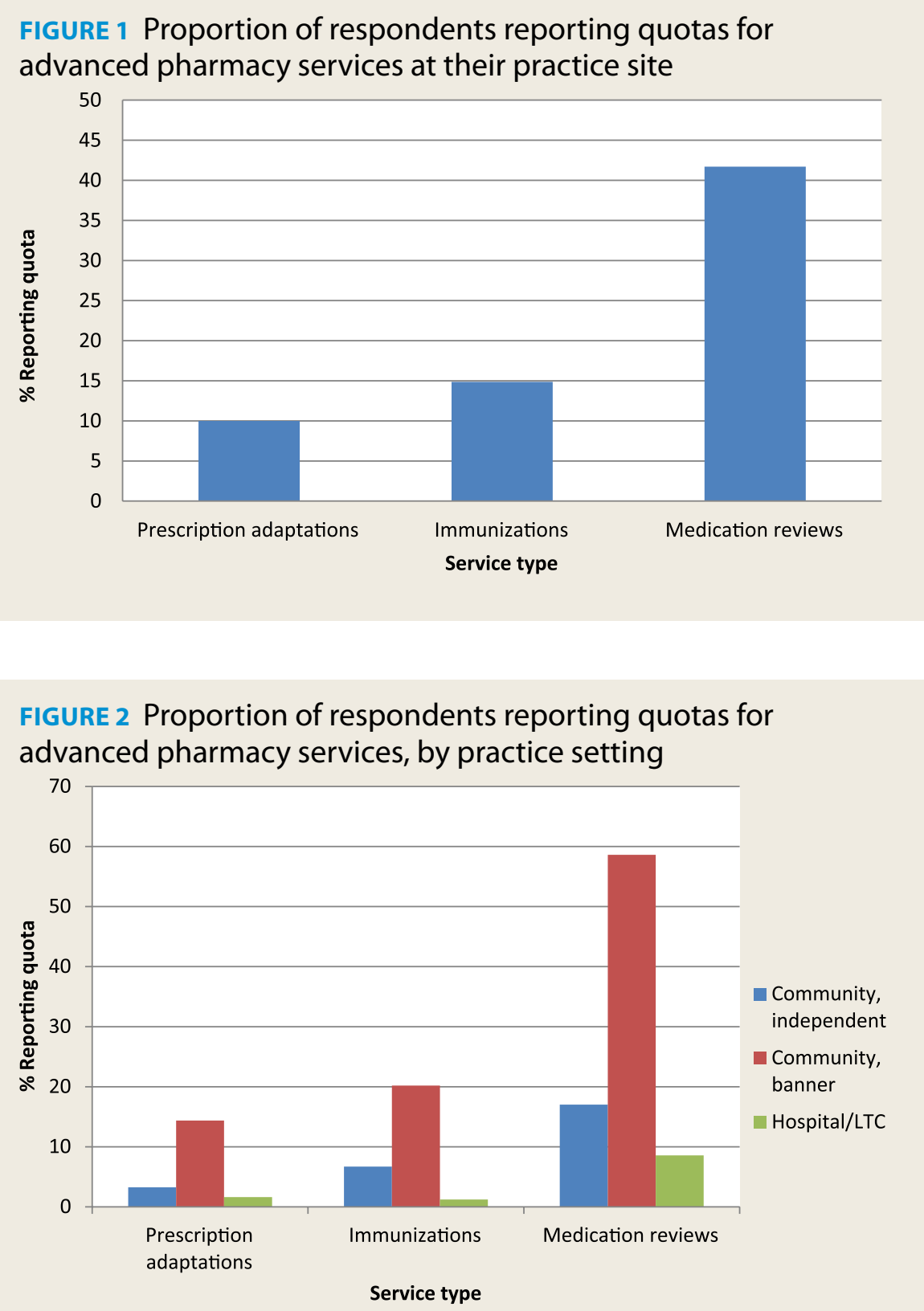

LTC, long-term care.

adjusting for other factors, we found that respondents' agreement with the workplace conditions statements differed significantly by practice setting, primary role, hours worked, average prescription wait time at their pharmacy, prescription volume and whether their workplace set quotas for advanced pharmacy services. Those working in independent community pharmacies, those who self-identified as clinical pharmacists or pharmacy managers, those working fewer hours and those at pharmacies with shorter prescription wait times or fewer prescription all tended to respond more positively regarding their workplace conditions. Those who worked at pharmacies where there were set quotas for advanced pharmacy services responded more negatively regarding their workplace conditions. There were no statistically significant differences in ratings of workplace conditions statements based on the age or sex of respondents.

Results from ordinal logistic regression models demonstrated that after adjusting for practice setting, primary role and prescription volume, pharmacists in workplaces with quotas for immunizations and medication reviews were twice as likely to disagree with the 
FIGURE 3 Mean monthly quotas for advanced pharmacy services, by respondent self-reported frequency of performing the services

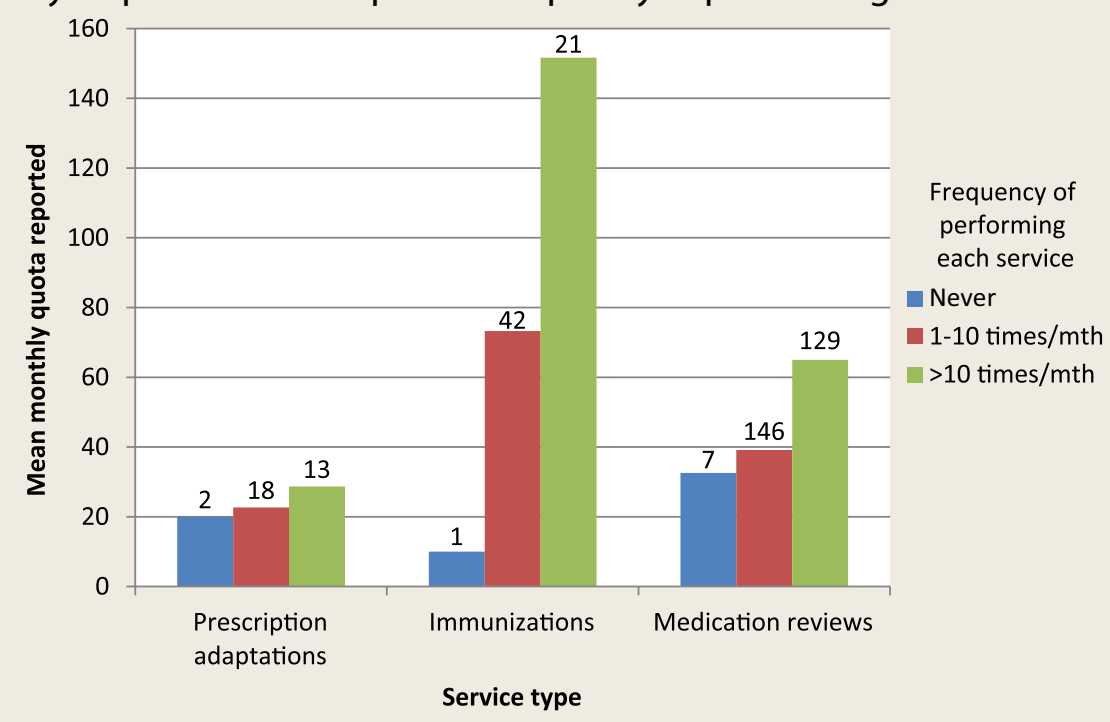

Numbers above bars indicate the number reporting.

statement that they had enough time for breaks and lunches as those from workplaces that did not have quotas (odds ratio $[\mathrm{OR}]=1.99,95 \%$ confidence interval $[\mathrm{CI}]=1.14-3.46$ and $\mathrm{OR}=$ $2.54,95 \% \mathrm{CI}=1.77-3.65$, respectively, as seen in Figure 4A). Compared with pharmacists who have been registered longer, recently registered pharmacists were more likely to report not having enough time for breaks and lunches (Figure 4A). Pharmacists in workplaces with quotas for prescription adaptations and medication reviews were almost twice as likely to report not having enough time to do their jobs relative to those from workplaces that did not have quotas $(\mathrm{OR}=$ $1.88,95 \% \mathrm{CI}=1.07-3.32$ and $\mathrm{OR}=1.86,95 \%$ $\mathrm{CI}=1.32-2.63$, respectively, as seen in Figure 4B). Similarly, those who were in pharmacies with higher prescription counts per pharmacist (prescription volume) were more likely to report not having enough time to do their jobs (OR = $1.48,95 \% \mathrm{CI}=1.17-1.88)$. Pharmacists working in independent pharmacies compared with those at chain pharmacies were half as likely to report not having enough time for their job $(\mathrm{OR}=0.54$, $95 \% \mathrm{CI}=0.37-0.79$; Figure $4 \mathrm{~B}$ ).

We found that pharmacists in workplaces with quotas for immunizations and medication reviews and higher prescription volume were all more likely to report that their work environment was not conducive to safe and effective patient care $(\mathrm{OR}=1.84,95 \% \mathrm{CI}=1.31-2.59 ; \mathrm{OR}=2.00$, $95 \% \mathrm{CI}=1.25-3.20$; and $\mathrm{OR}=1.38,95 \% \mathrm{CI}=$
1.10-1.75, respectively), while those working in independent pharmacies or hospital pharmacies/ long-term care settings, compared with those in chain pharmacies, were less likely to report a work environment that was not conducive to safe and effective patient care $(\mathrm{OR}=0.48,95 \% \mathrm{CI}=$ 0.32-0.72 and $\mathrm{OR}=0.57,95 \% \mathrm{CI}=0.33-0.99$, respectively, as seen in Figure $4 \mathrm{C}$ ). Pharmacists in workplaces with quotas for medication reviews $(\mathrm{OR}=2.04,95 \% \mathrm{CI}=1.45-2.87)$ and prescription adaptations $(\mathrm{OR}=1.80,95 \% \mathrm{CI}=1.06-3.05)$ (but not for immunizations) and higher prescription volume $(\mathrm{OR}=1.76,95 \% \mathrm{CI}=1.39-2.24)$ were all more likely to disagree that there was adequate pharmacist staffing to provide safe and effective patient care at their pharmacies (Figure 4d). Pharmacists working in independent pharmacies were less likely to report not having adequate pharmacist staffing compared with their counterparts from chain pharmacies $(\mathrm{OR}=0.39$, 95\% CI $=0.26-0.59$ ) (Figure $4 \mathrm{~d}$ ). Pharmacists in workplaces with quotas for immunizations $(\mathrm{OR}=2.30,95 \% \mathrm{CI}=1.43-3.74)$ and medication reviews $(\mathrm{OR}=1.42,95 \% \mathrm{CI}=1.02-1.99)$ (but not for prescription adaptations) and higher prescription volume $(\mathrm{OR}=1.29,95 \% \mathrm{CI}=1.03$ 1.62) were all more likely to disagree that they had adequate technician staffing to provide safe and effective patient care at their pharmacies (Figure 4E). Pharmacists working in independent pharmacies were less likely to report not having adequate technician staffing compared with 
TABLE 3 Proportion of respondents agreeing/disagreeing with working conditions statements

\begin{tabular}{|c|c|c|c|}
\hline & \multicolumn{3}{|c|}{ Proportion \% $(n=1016)$} \\
\hline & $\begin{array}{l}\text { Agree/strongly } \\
\text { agree }\end{array}$ & Neutral & $\begin{array}{l}\text { Disagree/ } \\
\text { strongly disagree }\end{array}$ \\
\hline "I have adequate time for break/lunches at my primary practice site" & 40 & 13 & 48 \\
\hline "I am satisfied with the amount of time I have to do my job" & 34 & 21 & 45 \\
\hline $\begin{array}{l}\text { "My employer provides a work environment that is conducive to safe and } \\
\text { effective primary care” }\end{array}$ & 47 & 25 & 28 \\
\hline $\begin{array}{l}\text { "My site has adequate pharmacist staff to provide safe and effective } \\
\text { patient care" }\end{array}$ & 41 & 23 & 36 \\
\hline $\begin{array}{l}\text { "My site has adequate technician staff to provide safe and effective patient } \\
\text { care" }\end{array}$ & 32 & 33 & 35 \\
\hline $\begin{array}{l}\text { "My site has adequate assistant staff to provide safe and effective patient } \\
\text { care" }\end{array}$ & 45 & 24 & 31 \\
\hline
\end{tabular}

their counterparts from chain pharmacies (OR $=0.67,95 \% \mathrm{CI}=0.46-0.97$ ) (Figure $4 \mathrm{E}$ ). We found nearly the exact trends, that pharmacists in workplaces with quotas for immunizations $(\mathrm{OR}=2.25,95 \% \mathrm{CI}=1.40-3.62)$ and medication reviews $(\mathrm{OR}=1.79,95 \% \mathrm{CI}=1.27-2.51)$ (but not for prescription adaptations) were more likely to disagree with having adequate assistant staffing to provide safe and effective patient care at their pharmacies (Figure 4E). Pharmacists working in independent pharmacies were also less likely to report not having adequate assistant staffing compared with pharmacists working in chain pharmacies $(\mathrm{OR}=0.51,95 \% \mathrm{CI}=0.34-0.76$; Figure 4F).

\section{Discussion}

This is the first study to show that pharmacists' self-reported workplace conditions in British Columbia are generally suboptimal. We found that many pharmacists expressed concerns regarding having enough time for breaks or lunches, enough time to do their jobs and enough staffing support. Pharmacists' perceptions of their workplace environment were found to be negatively associated with workplace-imposed advanced service quotas (for medication reviews, immunizations and prescription adaptations), being employed at chain stores compared with independent pharmacies or hospitals/long-term care settings and higher prescription volume.
These findings are in general agreement with those from around the globe. Workplace stress has been described as a major cause of occupational ill health and human error and has been a growing concern in community pharmacy practice. $^{14}$ Pharmacists from the United Kingdom reported significantly higher levels of workplace stressors than the general working population. A body of literature on this issue has originated from the United Kingdom since the implementation of the general pharmaceutical services contract (GPSC) for England and Wales in April 2005. The GPSC is similar to the newly introduced advanced pharmacy services in BCit includes (optional) enhanced services such as seasonal influenza vaccination, medicines use review and prescription intervention services, among others. ${ }^{15}$ Since its introduction, there have been concerns about the effect of the increasing workload on pharmacists' well-being, working conditions and patient safety in the United Kingdom. The United Kingdom saw a 589\% increase in medicine use reviews from 2005-06 to 2007-08, and dispensing volume has also been increasing steadily over the past 10 years, but growth in the supply of pharmacists is only $2 \%$ a year-resulting in demand grossly outweighing supply. ${ }^{16}$

Most studies to date have only explored the relationship between prescription dispensing volume and pharmacists' well-being and 
FIGURE 4 Associations between workplace factors and disagreement with working condition questions. (A) Time for breaks/lunches. (B) Time for job tasks. (C) Work environment for safe and effective care.

(D) Adequate pharmacist staffing. (E) Adequate technician staffing. (F) Adequate assistant staffing
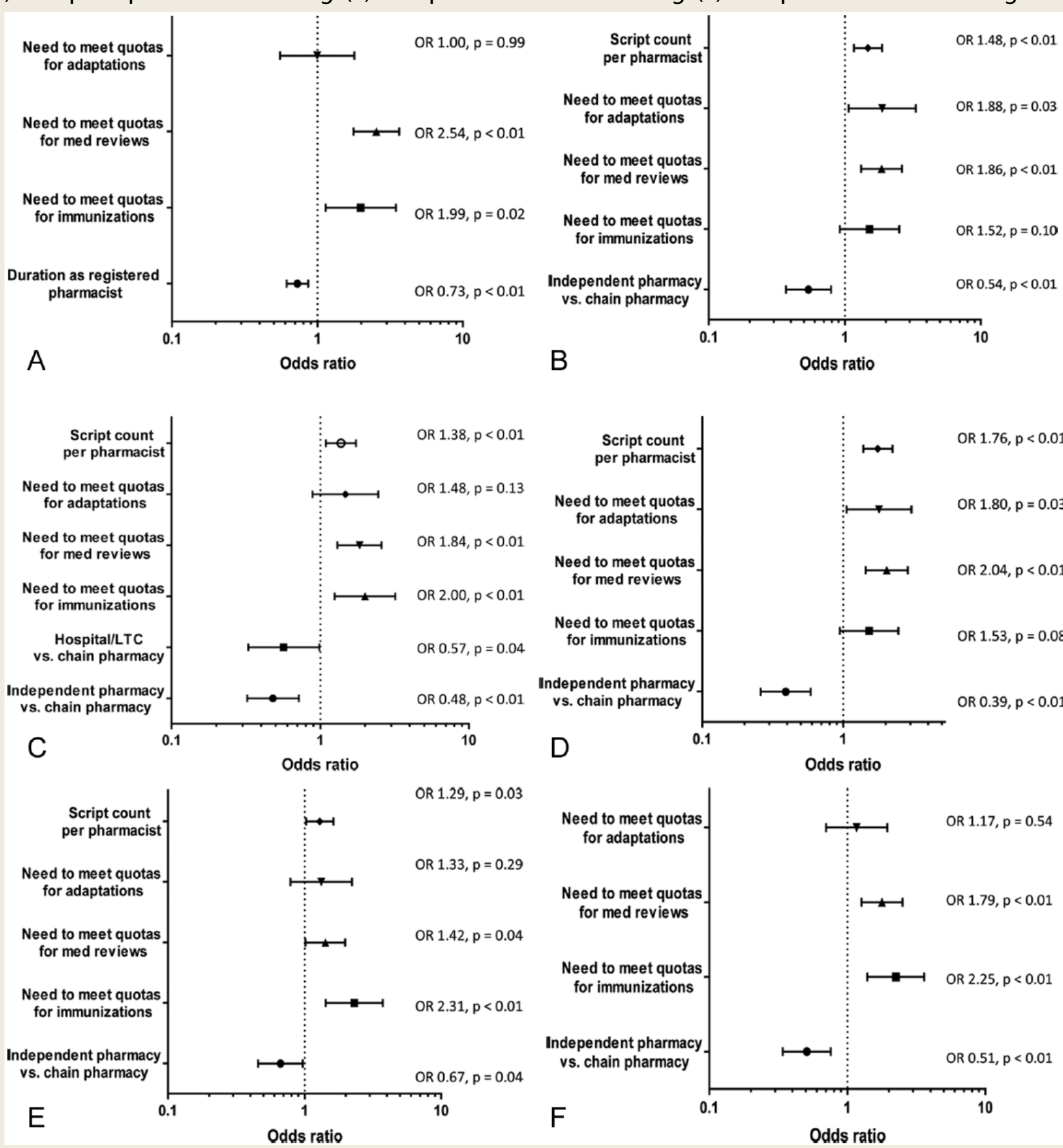

LTC, long-term care; OR, odds ratio.

patient safety. It has been established that increased prescription volume is associated with increased dispensing errors or near misses, thus compromising patient safety. ${ }^{17}$ This is corroborated by our findings that higher prescription count per pharmacist is associated with higher likelihood of pharmacists' perceiving their work environment to be unsafe for patient care.

A recent review of community pharmacy workload in the United Kingdom and its impact on patient safety and pharmacists' well-being concluded that while pharmacists still spend most 
of their time processing prescriptions, increased workload around clinical services and expanded scope has increased their overall work-related stress and decreased their sense of well-being.

Despite the shifting role of the pharmacist away from dispensing and the introduction of advanced pharmacy services, few studies to date have explored the relationship between volume (or frequency) of advanced pharmacy services and pharmacists' perception of the quality of patient care. Some anecdotal evidence in the United Kingdom suggests that corporate pressures on community pharmacies to reach targets for medicine use reviews regardless of clinical appropriateness have compromised quality of care. ${ }^{18,19}$ In our study, we did not find statistically significant relationships between frequency of advanced service provision and pharmacists' perception of a work environment unsafe for patient care. Rather, we found that it is the pressures of workplace-imposed quotas or targets for these services that have the biggest demonstrable impact on perception of safe patient care. The relationship is likely more complex, involving pharmacists' own perceived work-related stress, which has been stated to include not only pressures to achieve service quotas and targets, lack of breaks and support staff, but also stressors including lack of management support, organizational culture putting profit before patient care and patient demands. ${ }^{14}$ Potentially further complicating the situation is the finding that a subset of pharmacists who reported having higher mean monthly quotas for advanced pharmacy services also reported providing those services more frequently. This partly supported anecdotal comments from $\mathrm{BC}$ corporate pharmacies to the $\mathrm{CPBC}$ that claimed that quotas were implemented to motivate pharmacists to provide advanced services. ${ }^{20}$ However, alternative approaches to incentivise pharmacists and support pharmacists in providing advanced pharmacy services in a safe and effective manner should be considered in light of our wider findings.

Some limitations to this study should be noted. The response rate to the survey was relatively low. As such, it is not possible to state whether or not these results are generalizable to the larger pharmacist population in British Columbia. However, according to the Canadian Institute of Health Information's 2011 report, 57\% of BC pharmacists were female, and pharmacists' mean age was 42 years. ${ }^{21} \mathrm{~A}$ recent survey from the BC Pharmacists Association found that $66 \%$ of pharmacists in BC worked in chain community pharmacies, and $56 \%$ of respondents identified as staff pharmacists. ${ }^{22}$ Both of these characteristics agree with our sample and suggest that respondents from this study were generally representative of $\mathrm{BC}$ pharmacists. But the main limitation of our study and those in the published literature is that there is not yet a robust approach to ascertaining the quality and safety of advanced pharmacy services, leading to the challenge of establishing a direct link between perceived workplace pressures or targets and quality of patient care. Further exploration is warranted to determine the impact on the safety and effectiveness of patient care under the changing landscape of pharmacy practice.

\section{Conclusion}

Across Canada, there has been expansion in the scope of pharmacist services. There has been concern that the addition of these services to those already being performed by busy pharmacists could result in suboptimal conditions. In this study, we have shown that, in general, pharmacists in $\mathrm{BC}$ reported that they did not have enough time for breaks/lunches, enough time for job tasks and adequate pharmacist staffing. These and other self-reported indicators of workplace conditions were significantly associated with workplace location and having quotas in place for expanded scope services. As such, it would seem that certain pharmacies (especially those associated with chains) are seizing the financial opportunity of expanded scope without incorporating sufficient staff or adjusting workflow. Future research should determine if these self-reported workplace conditions actually translate into inferior patient care. 
of British Columbia (Nakagawa), Vancouver, BC; and the School of Pharmacy (Marra), Memorial University of Newfoundland, St. John's, NL. Contact cmarra@mun.ca.

Author Contributions: NW Tsao contributed to survey development, data collection, data analysis, interpretation of the findings, and drafted the manuscript. L. Gastonguay contributed to the survey development, interpretation of the findings, and editing of the manuscript. K. Li contributed to analysis of the data and edited the manuscript. CA Marra and B. Nakagawa conceived the study and obtained/ provided funding. CA Marra, B. Nakagawa and LD Lynd contributed to the survey development, reviewed and interpreted the findings, and edited the manuscript.

Declaration of Conflicting Interests: The authors declared no potential conflicts of interest with respect to the research, authorship and/or publication of this article.

Funding: This work was supported by the College of Pharmacists of British Columbia [grant number F13-03108].

\section{References}

1. Schafheutle EI, Seston EM, Hassell K. Factors influencing pharmacist performance: a review of the peer-reviewed literature. Health Policy 2011;102:178-92.

2. Jacobs S, Hassell K, Ashcroft D, et al. Workplace stress in community pharmacies in England: associations with individual, organizational and job characteristics. $J$ Health Serv Res Policy 2014;19:27-33.

3. Bond CA, Raehl CL. Pharmacists' assessment of dispensing errors: risk factors, practice sites, professional functions and satisfaction. Pharmacotherapy 2001;21:614-26.

4. Peterson GM, Wu MSH, Bergin JK. Pharmacists' attitudes towards dispensing errors: their causes and prevention. J Clin Pharm Therapeutics 1999;24:57-71.

5. McDonald R, Cheraghi-Sohi S, Sanders C, Ashcroft D. Professional status in a changing world: the case of medicines use reviews in English community pharmacy. Soc Sci Med 2010;71:451-8.

6. Cooksey JA, Knapp KK, Walton SM, Cultice JM. Challenges to the pharmacist profession from escalating pharmaceutical demand. Health Aff (Millwood) 2002;21:182-8.

7. Department of Health \& Human Services Heath Resources and Services Administration, Bureau of Health Professions. The pharmacist workforce: a study of the supply and demand for pharmacists. Available: http://bhpr.hrsa.gov/healthwork force/reports/pharmaciststudy.pdf (accessed February 13, 2015).

8. Gidman W. Exploring the impact of evolving health policy on independent pharmacy ownership in England. Pharm World Sci 2010;32:488-95.

9. McCann L, Adair CG, Hughes CM. An exploration of workrelated stress in Northern Ireland community pharmacy: a qualitative study. Int J Pharm Pract 2009;17:261-7.

10. Ashcroft DM, Quinlan P, Blenkinsopp A. Prospective study of the incidence, nature and causes of dispensing errors in community pharmacies. Pharmacoepidemiol Drug Saf 2005;14:327-32.

11. Oregon Board of Pharmacy. Oregon Board of Pharmacy Workload Survey. November 2013. Available: www.oregon. gov/pharmacy/Imports/OBOP-Pharmacy_Working_
Conditions_Survey_Results11.13.pdf (accessed August 18, 2014).

12. Oregon Board of Pharmacy. Oregon state board of pharmacy news. 2012. Available: www.nabp.net/publications/ assets/OR112012.pdf (accessed March 20, 2015).

13. Oregon Board of Pharmacy. Oregon Board of Pharmacy receives NABP award. The Lund Report. 2014. Available: https://www.thelundreport.org/content/oregon-boardpharmacy-receives-nabp-award (accessed March 20, 2015).

14. Jacobs, S, Hassell, K, Ashcroft, D, et al. Perceived causes and effects of workplace stress in community pharmacy: findings from a postal survey of community pharmacists. Int J Pharm Pract 2011;19(Suppl 2):100-1.

15. Pharmaceutical Services Negotiating Committee. 4 service domains. 2015. Available: http://psnc.org.uk/servicescommissioning/4-service-domains/ (accessed February 16, 2015).

16. Hassell K, Seston EM, Schafheutle EI, et al. Workload in community pharmacies in the UK and its impact on patient safety and pharmacists' well-being: a review of the evidence. Health Soc Care Comm 2011;19:561-75.

17. Johnson SJ, O'Connor EM, Jacobs S, et al. The relationships among work stress, strain and self-reported errors in UK community pharmacy. Res Social Adm Pharm 2014;10:885-95. 18. Gilpin LK. Improve pharmacists' working conditions. Pharmaceut J 2008;280:439.

19. Jukes AJ. Heavy workload is taking its toll. Pharmaceut J 2008;280:305.

20. College of Pharmacists of British Columbia. Board highlights: February 19 and 20, 2015. Available: http:// library.bcpharmacists.org/A-About_Us/A-4_Board/Board_ Highlights_20150219.pdf (accessed March 20, 2015).

21. Canadian Institutes of Health Information. Pharmacists in Canada-national and jurisdictional highlights. 2011. Available: http://www.cihi.ca/CIHI-ext-portal/pdf/internet/ PHARM_2011_HIGHLIGHTS_PROF_EN (accessed February 18, 2015).

22. BC Pharmacists Association. Wage and benefit survey. May 2013. Available: www.bcpharmacy.ca/uploads/members /2013WB_survey_FINAL.pdf (accessed February 18, 2015). 